\title{
a-GLUCOSIDASE INHIBITORY EFFECT OF SULOCHRIN FROM ASPERGILLUSTERREUS AND ITSBROMINATED DERIVATIVES
}

\author{
RiznaTriana Dewi*, Akhmad Darmawan, Hani Mulyani, Puspa Dewi N Lotulung, \\ Minarti, and Megawati
}

Research Center for Chemistry - Indonesian Institute of Sciences, Kawasan PUSPIPTEK Serpong, Tangerang Selatan, Banten 15314, Indonesia

*Corresponding author:rizn001@lipi.go.id; riznatd@gmail.com . Tel: +62-21 7560929

Received: $12^{\text {th }}$ Jan 2017 Revised: $27^{\text {th }}$ Nov $2017 \& 28^{\text {th }}$ Feb 2018 Accepted: $12^{\text {th }}$ March 2018

DOI: https://doi.org/10.22452/mjs.vol37no1.5

\begin{abstract}
Use of $\alpha$-glucosidase inhibitorsis one of the therapeutic approaches for decreasing postprandial hyperglycemia. Sulochrin (1) from Aspergillus terreus as well as two synthetic sulochrin derivatives were assessed for antidiabetic activity against yeast and rat intestine $\alpha$-glucosidase. Sulochrin showed potential inhibition against yeast $\alpha$-glucosidase, through a non-competitive mode with an $\mathrm{IC}_{50}$ value of $133.79 \mu \mathrm{M}$, and rat intestine $\alpha$ glucosidase by uncompetitive mode with an $\mathrm{IC}_{50}$ value of $144.59 \mu \mathrm{M}$.. Two synthetic derivatives of sulochrin were also prepared by bromination which resulted in dibromosulochrin (2) and tribromo-sulochrin (3). Preliminary SAR studies of sulochrin derivatives revealed that the yeast $\alpha$-glucosidase inhibitory activity of compound $\mathbf{2}$ and $\mathbf{3}$ increased than 1 due to substitution of hydrogen atom with bromine with $\mathrm{IC}_{50}$ values of 122.65 and 49.08 $\mu \mathrm{M}$, respectively. However, the inhibitory activity against rat intestine $\alpha$-glucosidase of $\mathbf{2}$ and 3 was decreased compared to 1. To the best our knowledge, this is the first report of structure-activity relationship of sulochrin and its derivatives as $\alpha$-glucosidase inhibitors. These results suggested that sulochrin can potentially be used as a lead compound to develop new $\alpha$-glucosidase inhibitor from microorganisms.
\end{abstract}

Keywords: Aspergillus terreus, $\alpha$-glucosidase inhibitory activity, sulochrin, bromination

\section{INTRODUCTION}

Type-2 diabetes is the most common form of diabetes, accounting for $90 \%$ of cases, and is usually characterized by an abnormal rise in blood sugar right after a meal, called postprandial hyperglycemia(Nguyen et al., 2011). $\alpha$ Glucosidase inhibitorsare one of the therapeutic approaches in decreasing postprandial hyperglycemia by delaying the digestion of poly-and oligosaccharides to absorbable monosacharides (Takahashi \& Miyazawa, 2012). Furthermore, glucosidase inhibitors have been a huge concern to researchers working in the field of medicinal chemistry since their antidiabetic and antiobesity activity, is also associated with their activity against HIV and hepatitis (Mehta et al., 1998; Du et al., 2006; Zhu et al., 2008). Acarbose is a compound isolated from Actinoplanes utahanensis that has been attributed with a 
decrease of postprandial blood glucose and used as medicine for treating patients with type 2diabetes (Fujisawa et al., 2005; Kim et al., 2005). However, long-term administration of acarbose has been associated with diarrhea, abdominal gas, liver toxicity, and adverse gastrointestinal symptoms that would increase the risks of liver diseases (Kim et al., 2008). Therefore, research on the exploration of new $\alpha$-glucosidase inhibitor for further drug development is still necessary.

Aspergillus terreus is a common soil saprophyte was isolated from both marine and terrestrial sources with worldwide distribution and its studies were first published in 1918 (Wang et al., 2008). A statin drug, lovastatin, an inhibitor of 3-hydroxy-3-methylglutarylcoenzyme A reductase is known for its cholesterol-lowering effect used in the treatment of heart disease and atherosclerosis, is mainly produced by $A$. terreus (Hajaj et al., 2001). Recently, we have reported that butyrolactone I and aspulvinone $\mathrm{E}$ isolated from an ethyl acetate extract of $A$. terreus showed potential inhibitory activity against $\alpha$ glucosidase (Dewi et al., 2014; Dewi et al., 2015). As part of our research program on the utilization of bioresources in Indonesia, we have been screening extracts of A. terreus for in vitro antidiabetic activity, namely for $\alpha$-glucosidase inhibitory activity. In one of our previous study, extract of A. terreus exhibited a significant inhibitory effect against yeast $\alpha$-glucosidase and suppressed postprandial hyperglycemia in mice (Dewi et al., 2007). Therefore, we selected the strain for large scale fermentation with a view to isolate the active compound and study the effect on bioactivity upon bromination.
The effect of isolated and derived compounds was evaluated on yeast and mammalian $\alpha$-glucosidase by in vitro assay. The structure-activity relationships and kinetics of inhibitory activity of active compounds were also discussed.

\section{MATERIALS AND METHODS}

\section{General instrumentsand reagents}

Melting points were measured on a Yanaco micro melting point apparatus (Yanaco Co., Ltd., Kyoto, Japan) and were uncorrected. The mass spectra of the compounds were measured with Mariner Liquid Chromatography - Mass Spectrometer. The nuclear magnetic resonance (NMR) spectra were recorded at $500 \mathrm{MHz}$ for ${ }^{1} \mathrm{H}$ and $125 \mathrm{MHz}$ for ${ }^{13} \mathrm{C}$ on a JEOL JNM-ECA 500 using $\mathrm{CD}_{3} \mathrm{OD}$ as solvent, with TMS as internal standard. HMQC and HMBC techniques were used to assign correlations between ${ }^{1} \mathrm{H}$ and ${ }^{13} \mathrm{C}$ signals. The chemical shift values $(\delta)$ are given in parts per million (ppm), and coupling constant $(J)$ in $\mathrm{Hz}$. Chromatography column was carried out using Merck Si-gel 60 and TLC analysis on pre-coated Si-gel plates (Merck Kieselgel $60 \mathrm{~F}_{254}$ ) and spots were detected under UV light. All solvents used were analytical grade and distilled prior to use.

$\alpha$-Glucosidase Type I: from yeast Saccharomyces cerevisiae (EC 3.2.1.20), bovine serum albumin and $p$-nitrophenyl$\alpha$-D-glucopyranoside ( $p$-NPG) as synthetic substrate of $\alpha$-glucosidase were purchased from Wako Pure Chemical Industries, Ltd (Osaka, Japan). $\quad \alpha$-Glucosidase Type II rat intestinal acetone powder (as source of 
crude intestinal $\alpha$-glucosidase), benzyltrimethylammoniumtri-bromide (BTMAT-Br), and corn step liquor were obtained from Sigma-Aldrich.

\section{Fungal material}

A. terreus, a mutant developed from ATCC 20542, was obtained from the Research Center for Chemistry, Indonesian Institute of Sciences (RCC-LIPI), Indonesia. The voucher specimen was deposited at RCC-LIPI at $-20^{\circ} \mathrm{C}$, whereas working stocks were prepared on MY agar (malt extract $1 \%$, yeast extract $0.4 \%$, dextrose $0.4 \%$, and agar $2 \%$ ) stored at $4{ }^{\circ} \mathrm{C}$.

\section{Extraction and isolation}

The solid state fermentation was done as described in our previous report (Dewiet al., 2007). The solid state fermentation $(30 \mathrm{Kg})$ product was extracted with EtOAc (15 L). The EtOAc extract was concentrated to obtain brown paste $(500 \mathrm{~g})$. After the addition of water: $\mathrm{MeOH}(4: 1)(500 \mathrm{~mL})$, the solution was partitioned with $n$-hexane (1 L), $\mathrm{CH}_{2} \mathrm{Cl}_{2}$ (5 L), and EtOAc (3 L) successively and concentrated subsequently. Organic fractions were subjected to primary $\alpha$-glucosidase inhibitory activity screening, and EtOAc fraction was found to be the most active (Fig. 1). The EtOAc fraction (25 g) was applied to a silica gel column chromatography (CC) eluted with a linear gradient concentration of $n$-hexane/EtOAc from $10 \%$ to $100 \%$ to obtain ten fractions (F1-F10). Fraction $6 \quad(6.5$ g) was rechromatographed on a silica gel $\mathrm{CC}$ eluted using a stepwise gradient from $70 \%$ $n$-hexane in EtOAc to $100 \%$ EtOAc to give eight fractions (F6.1-F6.8). Further separation of fraction F6.5 by chromatography on a silica gel column, eluted with isocratic elution of $\mathrm{CHCl}_{3}: \mathrm{MeOH} \quad(3: 1)$ followed by recrystallization from $\mathrm{MeOH}$ yielded yellowish solid compound $\mathbf{1}$ (3 g).

\section{Preparation of sulochrinderivatives}

Derivatization of sulochrin (1) was conducted by bromination and cyclization. Bromination of $\mathbf{1}$ was carried out according to the method of Sato et al.(2005). Compound 1 (40 mg, 0.12 mmol) was dissolved in $\mathrm{CHCl}_{3} / \mathrm{MeOH}$ (1 $\mathrm{mL}$ ), mixed with $\mathrm{CaCO}_{3}$ (25 mg, 0.25 mmol) and benzyltrimethylammoniumtribromide (BTMAT-Br) (95 mg, $0.24 \mathrm{mmol}$ ). After 30 min of stirring at room temperature, the reaction mixture was added with $\mathrm{CHCl}_{3}$, and washed with $5 \% \mathrm{HCl}$. The organic layer was dried over $\mathrm{Na}_{2} \mathrm{SO}_{4}$ and concentrated. The residue was purified by recrystalization from $\mathrm{CHCl}_{3}$ and $\mathrm{MeOH}$, generating dibromo-sulochrin (2) $(22 \mathrm{mg}$, $37 \%$ ) as yellowish solid and tribromosulochrin (3) (29 $\mathrm{mg}, 42.5 \%$ ) as yellow needle, where the substitution occurs on atoms C-3 and C-5 fordibromo-sulochrin (2), and atoms C-3, C-5 and C-6' for tribromo-sulochrin (3).

\section{Characterization of the isolated compound and its brominated derivatives}

Compound (1):Sulochrin: Methyl2(2',6'-dihydroxy-4'-methylbenzyl-)5-

hydroxy-3-methoxybenzoate), yellow solid; mp $262^{\circ} \mathrm{C}$; UV $\lambda_{\max }^{\mathrm{MeOH}} 283 \mathrm{~nm}$. FTIR (KBr) $\mathrm{V}_{\max }$ 3358, 3086, 2918, 1691, $1593 \mathrm{~cm}^{-1}$. Molecular formula $\mathrm{C}_{17} \mathrm{H}_{16} \mathrm{O}_{7}$ $\left(\mathrm{m} / \mathrm{z} 333.08[\mathrm{M}+\mathrm{H}]^{+}\right) .{ }^{1} \mathrm{H}-\mathrm{NMR}(500 \mathrm{MHz}$, $\left.\mathrm{CD}_{3} \mathrm{OD}\right) \delta: 2.18$ (3H,s, H-11), 3.65 (3H,s, $\mathrm{H}-1), 3.68$ (3H,s, H-10), 6.09 (2H,s, H3'/5'), 6.64 (1H, d, J=2 Hz, H-4), 6.93 $(1 \mathrm{H}, \quad \mathrm{d}, \quad J=2 \mathrm{~Hz}, \mathrm{H}-6) .{ }^{13} \mathrm{C}-\mathrm{NMR} \quad(125$ 
$\left.\mathrm{MHz}, \mathrm{CD}_{3} \mathrm{OD}\right) \delta: 20.7$ (C-11), 51.2 (C-9), 55.2 (C-10), 102.9 (C-4), 107.4 (2C, C3'/5'), 109.5 (C-6), 110.5 (C-1'), 126.7 (C2), 128.5 (C-1), 147.9 (C-4'), 157.3 (C-3), 158.3 (C-4), 162.0 (2C, C-6'/2'), 166.7 (C8), and 200.7 (C-7).

\section{Compound (2): Dibromo-sulochrin:} Methyl 2-(3',5'-dibromo-2',6'-dihydroxy4'-methylbenzyl-)5-hydroxy-3-

methoxybenzoate), yellowish solid, $\mathrm{mp}$ $197-199^{\circ} \mathrm{C}$; UV $\lambda_{\max }^{\mathrm{MeOH}} 270$ and $353 \mathrm{~nm}$. FTIR (KBr) $V_{\max } 3390,2924,1691,1579$, $659 \mathrm{~cm}^{-1}$. Molecular formula $\mathrm{C}_{17} \mathrm{H}_{14} \mathrm{Br}_{2} \mathrm{O}_{7}$ $\left(\mathrm{m} / \mathrm{z} 488.08[\mathrm{M}+\mathrm{H}]^{+}\right) .{ }^{1} \mathrm{H}-\mathrm{NMR}(500 \mathrm{MHz}$, $\left.\mathrm{CD}_{3} \mathrm{OD}\right) \delta: 2.18(3 \mathrm{H}, \mathrm{s}, \mathrm{H}-11), 3.65(3 \mathrm{H}, \mathrm{s}$, H-9),3.68 (3H,s, H-10), 6.64 (1H, d, J=2 $\mathrm{Hz}, \mathrm{H}-4), 6.93$ (1H, d, J=2Hz, H-6). ${ }^{13} \mathrm{C}-$ NMR (125 MHz,CD $\left.{ }_{3} \mathrm{OD}\right) \delta: 25.7$ (C-11), 53.1 (C-9), 56.5 (C-10), 101.1 (2C, C3'/5'), 104.8 (C-4), 109.9 (C-6), 125.9 (C2), 132.6 (C-1), 145.9 (C-4'), 155.0 (C-3), 155.8 (2C, C-2'/6'), 157.5 (C-5), 166.1 (C8), and 196.8 (C-7).

\section{Compound (3): Tribromo-sulochrin:} Methyl 2-bromo-6-(3',5'-dibromo-2',6'dihydroxy-4'-methylbenzoyl-)5-hydroxy-

3-methoxybenzoate), yellow needles, mp $196-198^{\circ} \mathrm{C}$; UV $\lambda_{\max }^{\mathrm{MeOH}} 288,355 \mathrm{~nm}$. FTIR $(\mathrm{KBr}) \mathrm{V}_{\max } \quad 3296, \quad 2933,1689,1579$, $626 \mathrm{~cm}^{-1}$. Molecular formula $\mathrm{C}_{17} \mathrm{H}_{13} \mathrm{Br}_{3} \mathrm{O}_{7}$ $\left(\mathrm{m} / \mathrm{z} 566.54[\mathrm{M}+\mathrm{H}]^{+}\right) .{ }^{1} \mathrm{H}-\mathrm{NMR}(500 \mathrm{MHz}$, $\left.\mathrm{CD}_{3} \mathrm{OD}\right) \delta: 2.18(3 \mathrm{H}, \mathrm{s}, \mathrm{C}-11), 3.65(3 \mathrm{H}, \mathrm{s}$, H-9), 3.68 (3H,s, H-10), 6.64 (1H, d, J=2 $\mathrm{Hz}, \mathrm{H}-4) .{ }^{13} \mathrm{C}-\mathrm{NMR}$ (125 $\left.\mathrm{MHz}, \mathrm{CD}_{3} \mathrm{OD}\right)$ 8:25.7 (C-11), 49.3 (C-9, 49.4 (C-10), 101.7 (2C, C-3'/5'), 104.9 (C-4), 113.1 (C6), 125.3 (C-2), 136.2 (C-1), 146.5 (C-4'), 157.7 (C-3), 158.7 (C-5), 159.1 (2C, C2'/6'), 168.7 (C-8), and 198.4 (C-1).

\section{Yeast $\alpha$-glucosidase inhibitoryassay}

$\alpha$-Glucosidase inhibitory activity was evaluated according to thepreviously reported method (Dewi et al., 2014). 250 $\mu \mathrm{L} \alpha$-Glucosidase (0.124 unit/mL), $495 \mu \mathrm{L}$ of $0.1 \mathrm{M}$ phosphate buffer ( $\mathrm{pH} 7.0$ ), and 5 $\mu \mathrm{L}$ of various concentrations of samples in DMSO $(50-200 \mu \mathrm{g} / \mathrm{mL})$ were preincubated at $37^{\circ} \mathrm{C}$ for $5 \mathrm{~min}$. The reaction was initiated/triggered by the addition of $250 \mu \mathrm{L}$ of $5 \mathrm{mM} p$-NPG (Wako, Osaka, Japan). The reaction mixture was incubated at $37^{\circ} \mathrm{C}$ for $15 \mathrm{~min}$ and stopped by adding $1 \mathrm{~mL}$ of $0.1 \mathrm{M} \mathrm{Na}_{2} \mathrm{CO}_{3}$. $\alpha$ Glucosidase activity was determined by measuring the release of $p$-NPG at $410 \mathrm{~nm}$.

\section{Mammalian a-glucosidase inhibitory assay}

The inhibitory activity assay toward mammalian $\alpha$-glucosidase was as described by Sanchetietet al., (2011), with a slight modification, i.e: 0.5 grams of mammalian $\alpha$-glucosidase (Sigma, St. Louis, MO, USA) was suspended in 10 $\mathrm{mL}$ of $0.9 \%$ saline $(100: 1 \mathrm{w} / \mathrm{v})$, and the suspension was sonicated twelve times for 30 s each time at $4^{\circ} \mathrm{C}$ (properly). After centrifugation $\left(1000 \mathrm{~g}, 30 \mathrm{~min}, 4^{\circ} \mathrm{C}\right)$, the supernatant was used for the assay. Five microlitres of sample solution (50-200 $\mu \mathrm{g} / \mathrm{mL}$ ) was pre-incubated with $595 \mu \mathrm{L}$ of $0.1 \mathrm{M}$ phosphate buffer ( $\mathrm{pH} 7.0$ ), and 250 $\mu \mathrm{L}$ of $5 \mathrm{mM} p-\mathrm{NPG}$ solution in $0.1 \mathrm{M}$ phosphate buffer (pH 7.0). After preincubation at $37^{\circ} \mathrm{C}$ for $5 \mathrm{~min}, 150 \mu \mathrm{L}$ of mammalian $\alpha$-glucosidase solution was added. The reaction was then terminated by the addition of $1 \mathrm{~mL}$ of $0.2 \mathrm{M} \mathrm{Na}_{2} \mathrm{CO}_{3}$. The resulting absorbance wese recorded at $400 \mathrm{~nm}$. Individual blanks for test samples were prepared to correct background absorbance, in which the enzyme was 
replaced with $150 \mu \mathrm{L}$ of phosphate buffer. All the tests were run in triplicate. The percent inhibition of $\alpha$-glucosidase was assessed/determined using the following formula: \% Inhibition $=[1-(\mathrm{As} / \mathrm{Ao})]$ $\times 100$, where Ao is the absorbance of the control and As is the absorbance in presence of sample. The $\mathrm{IC}_{50}$ values were calculated from the mean inhibitory values by applying logarithmic regression analysis.

\section{Kinetics of inhibition against $\alpha$ - glucosidase}

The inhibitory activity of the active compounds against $\alpha$-glucosidase activity was measured with increasing concentrations of $p$-NPG as a substrate in the absence or presence of anactive compound at different concentrations. The type of inhibition was determined by Lineweaver-Burk plot analysis

\section{RESULTS AND DISCUSSION}

A pilot-scale fermentation of $A$. terreuswas made to obtain sufficient quantities of active components. After seven days of fermentation at $25^{\circ} \mathrm{C}, 500 \mathrm{~g}$ of EtOAc soluble material was extracted from $30 \mathrm{~kg}$ of the solid state (rice). Dried EtOAc extract (490 g) was sequentially partitioned with $n$-hexane, $\mathrm{CH}_{2} \mathrm{Cl}_{2}$ and EtOAc, respectively. The EtOAc fraction showed potential $\alpha$-glucosidase inhibitory activity with the $\mathrm{IC}_{50}$ value of $8,6 \mu \mathrm{g} / \mathrm{mL}$. The further separation by column chromatography afforded sulochrin as an active compound of EtOAc fraction. The isolated scheme ofsulochrin is shown in Figure 1. Compound $\mathbf{1}$ was identified as (2-(2,6-Dihydroxy-4-methyl-benzoyl)-5hydroxy-3-methoxy-benzoic acid methyl ester (sulochrin) by comparison of obtained spectra NMR data with published NMR data (Sato et al., 2005; Ohashi et al., 1997).

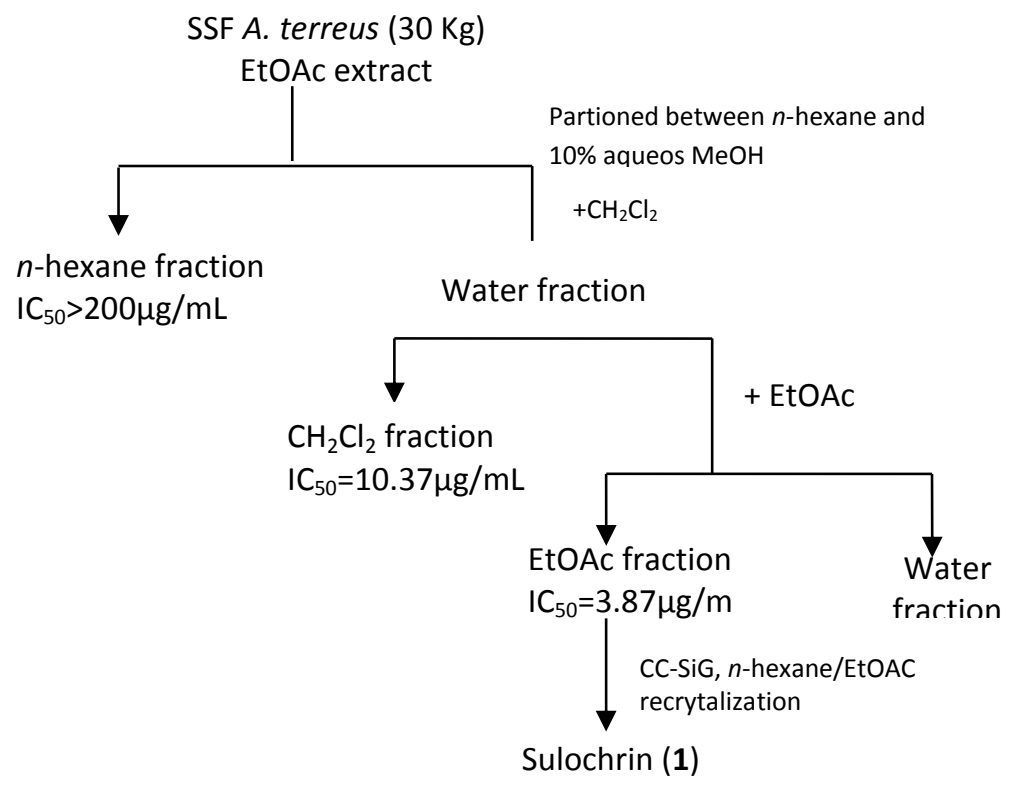

Figure. 1 Isolation procedure for sulochrin (1) 
Sulochrin (1) has a unique benzophenone scaffold, in which the four ortho positions are all substituted. This compound is known as a metabolite of fungi and has very weak antibacterial and antifungal activities (Ueno et al., 1998). Furthermore, Ohashiet al.(1997), have reported the inhibitory action on eosinophil degranulation by sulochrin and suggested it as a potentiallead for the development of newanti-allergic drug. However, the $\alpha$-glucosidase inhibitory activity of sulochrin has never been reported before.

In order to confirm the structure, sulochrin was derivatized by bromination (Figure 2). The bromination of compound 1 with BTMAT-Br resulted in the substitution of a hydrogen atom with bromide. Semisynthetic derivatization was conducted to verify the effect on bioactivity upon brominationof sulochrin and to provide a preliminary study of the structure-activity relationship of sulochrin. Compound 2 showed cluster peaks at $\mathrm{m} / \mathrm{z}$ 486,488 , and 490, which indicated that it was dibrominated, whereas compound $\mathbf{3}$ had cluster peaks at $m / z, 566,568,570$, and 572 , which suggested it was tribrominated (Kim et al., 2008). The molecular weight of 2 and 3 was different by 78 mass units which means compound $\mathbf{3}$ has undergone an extra $\mathrm{Br}$ substitution than compound 2 . A comparison of the ${ }^{1} \mathrm{H}$ and ${ }^{13} \mathrm{C}-\mathrm{NMR}$ spectra of compound $\mathbf{1}, \mathbf{2}$, and $\mathbf{3}$ showed similar patterns. The significant differences can be observed from the substitution of aromatic protons by bromine in compound $\mathbf{1}$ to produce compounds $\mathbf{2}$ and $\mathbf{3}$.<smiles>CC(=O)c1c(Br)c(O)cc(O)c1C(=O)c1c(O)cc(O)cc1OC(=O)c1cc(C)cc(O)c1C(=O)c1c(O)cc(O)cc1C(=O)c1c(O)cc(O)cc1C(=O)c1c(O)c(Br)c(C)c(Br)c1O</smiles>

Figure.2 Derivatization of sulochrin (1)

$\alpha$-Glucosidase (EC 3.2.1.20, $\alpha$-Dglucoside glucohydrolase) is an exo-type carbohydrase that catalyzes the liberation of $\alpha$-glucose from the nonreducing end of the substrate. Various types of $\alpha$ glucosidases are widely distributed in microorganisms, plants, and animal tissues and the substrate specificity of $\alpha$ glucosidases is known to differ greatly depending on their source (Kimura et al., 2004). $\alpha$-Glucosidase derived from bacterial, yeast (Saccharomyces cerevisiae) and insect enzymes, named $\alpha$ glucosidase I, show higher activity toward 
such heterogeneous substrates as sucrose and $p$-nitrophenyl $\alpha$-glucoside (PNPG), whereas $\alpha$-glucosidase from the mold, plant, and mammalian enzymes, named $\alpha$ glucosidase II, hydrolyze the homogeneous substrates more rapidly than the heterogeneous substrates (Kimura et al., 2004). In order to evaluate the activity and selectivity of sulochrin and and its semisynthetic derivatives ( 2 and $\mathbf{3}$ ) for the inhibitory effect on $\alpha$-glucosidase, yeast $S$. cerevisiae (I) and mammalian enzyme (II), were used. In this study, quercetinwas used as a standard due to several reports that quercetin, a phenolic compound, have stronger inhibitory activity on $\alpha$ glucosidase from yeast $S$. cerevisiae than acarbose(Tadera et al., 2006; Li et al., 2009), while we have used acarbose as the standardagainst mammalian $\alpha$-glucosidase.

$\alpha$-Glucosidase inhibitory activity of the compounds (1-3) obtained were measured using spectrometric method at concentrations 25-250 $\mu \mathrm{g} / \mathrm{mL}$. For each compound, the $\mathrm{IC}_{50}$ value was calculated and presented in Table 1. The results indicated that the substitution of ahydrogen atoms in sulochrinbybromine in compounds $\mathbf{2}$ and $\mathbf{3}$ enhanced the inhibitory activity against yeast $\alpha$ glucosidase. The $\mathrm{IC}_{50}$ values of compounds $\mathbf{2}$ and $\mathbf{3}$ against yeast $\alpha$ glucosidase were 122.65 and $49.08 \mu \mathrm{M}$, respectively, which were lower than that of sulochrin. This finding is similar to that of Kim et al. (2008) which showed that two bromophenol isolated from G. elliptica: 2,4,6-tribromophenolresulted in a higher inhibitory activity than 2,4dibromophenolagainst yeast $\alpha$-glucosidase. Liu et al.(2011), also reported that the activity of bromophenol has a close relationship with the $\mathrm{Br}$ and phenolic unit in the molecule, for example, 3-bromo-4,5dihydroxybenzyl alcohol inhibits against $\alpha$-glucosidase with $\mathrm{IC}_{50}$ of $100 \mu \mathrm{M}$, when one more position is brominated, the $\mathrm{IC}_{50}$ value decreases to $89 \mu \mathrm{M}$.So it can be assumed that the inhibitory activity of bromophenol increases with the degree of bromo-substitution per benzene ring. To the best of our knowledge, this is the first report of identifying $\alpha$-glucosidase inhibitory activity of sulochrin from $A$. terreusas well as dibromo- and tribromo derivative of sulochrin.

The inhibitory activity of active compounds against mammalian $\alpha$ glucosidase were also compared with those of acarbose and quercetin (Table 1).The $\mathrm{IC}_{50}$ value of acarbose was $67.93 \mu \mathrm{M}$, whereas the $\mathrm{IC}_{50}$ value of quercetin was $108.39 \mu \mathrm{M}$. On the other hand, all compounds showed weak inhibitory activity against mammalian $\alpha$ glucosidase,compared to that against yeast $\alpha$-glucosidase, except for sulochrin. Sulochrin showed similar inhibitory activity against both yeast and mammalian glucosidase with the $\mathrm{IC}_{50}$ values being 133.79 and $144.59 \mu \mathrm{M}$, respectively (Table 1). These results supported our previous study where sulochrinwas able to bind at the active site of $\alpha$-glucosidase enzyme in molecular docking approach (Dewi et al., 2009).

The mechanismfor the inhibitory activity of the isolated compounds wasanalyzed further using LineweaverBurk plots. The mode of inhibition of all active compounds againstyeast $\alpha$ glucosidasewas analysed from the data derived from enzyme assays containing different concentrations of $p$-NPG, ranging from 0.25 to $5 \mathrm{mM}$ of the compounds. 
Table $1 \alpha$-Glucosidase inhibitory activities of sulochrin and its derivatives

\begin{tabular}{ccr}
\hline Compound & \multicolumn{2}{c}{$\mathbf{I C}_{\mathbf{5 0}}(\boldsymbol{\mu M})^{\mathrm{a}}$} \\
\cline { 2 - 3 } & $\begin{array}{c}\text { Yeast } \boldsymbol{\alpha}- \\
\text { glucosidase }\end{array}$ & $\begin{array}{c}\text { Mammalian } \\
\boldsymbol{\alpha} \text {-glucosidase }\end{array}$ \\
\hline $\mathbf{1}$ & $133.79 \pm 1.5$ & $144.59 \pm 3.2$ \\
$\mathbf{2}$ & $122.65 \pm 1.3$ & $144.30 \pm 1.2$ \\
$\mathbf{3}$ & $49.08 \pm 0.7$ & $111.18 \pm 0.5$ \\
Quercetin & $25.83 \pm 1.3$ & $108.39 \pm 2.1$ \\
Acarbose & $\mathrm{NI}$ & $67.93 \pm 1.3$ \\
\hline a: The IC & value was defined as the inhibitor \\
concentration to inhibit 50\% of $\alpha$-glucosidase \\
activity under assay conditions. \\
NI: no inhibition.
\end{tabular}

The $1 / \mathrm{V}$ increased with the concentration of compound $\mathbf{1}$, but the $\mathrm{Km}$ remained constant (Figure 3a), suggesting non-competitive inhibition by compound 1. While compound $\mathbf{2}$ and $\mathbf{3}$ displayed a mixed mode inhibition (Figure $4 \mathrm{a}$ and 5a). The mixed type of inhibition was characterized by a combination of competitive and non-competitive inhibition, which indicated that compound $\mathbf{2}$ and $\mathbf{3}$ bind to a site other than the active site of the enzyme and interact with either the free enzyme or the enzyme-substrate complex, possibly interfering with the actions of both (Mayur et al., 2010). The inhibitory mechanism of those compounds was similar to that of quercetin (Tadera $e t$ al., 2006; Li et al., 2009) with $K i$ (inhibitory constant) value of $27.13 \mu \mathrm{M}$. The $K i$ values of compounds 1,2 , and 3 were 187.63, 131.25, and $117.20 \mathrm{mM}$, respectively (Table 2), which shows that compound $\mathbf{3}$ was the most effective in $\alpha$-glucosidase inhibition.

The inhibitory mechanisms of all compounds (1-3) against mammalian $\alpha$ glucosidase were shown in Figure $3 b, 4 b$, and $5 \mathrm{~b}$. The results showed a straight line parallel to the plot of $1 / \mathrm{V}$ versus $1 /[\mathrm{S}]$ indicating uncompetitive inhibition. While acarbose exhibited competitive type inhibition with $\mathrm{Ki}$ value of $0.06 \mu \mathrm{M}$. These different inhibitory activities may be caused by structural differences, as previously reported, $\alpha$-glucosidase broadly consists of type I from yeast $S$. cerevisiae and type II from the mammalian species, and there are homology analysis of the complete amino acid sequences differences between these types (Ueno et al., 1998).

Table 2 Type and kinetic constant of yeast and mammalian $\alpha$-glucosidase inhibition by sulochrin and its derivatives

\begin{tabular}{cllcc}
\hline \multirow{2}{*}{ Compond } & \multicolumn{2}{c}{ Inhibition mode } & \multicolumn{2}{c}{ Inhibition constans $($ Ki $\mu \mathrm{M})$} \\
\cline { 2 - 5 } & Yeast & $\begin{array}{l}\text { mammalian } \\
\alpha \text {-glucosidase }\end{array}$ & Yeast & $\begin{array}{c}\text { mammalian } \\
\alpha \text {-glucosidase }\end{array}$ \\
\hline $\mathbf{1}$ & Non-compettive & Uncompetitive & 187.63 & 85.42 \\
$\mathbf{2}$ & Mixed type & Uncompetitive & 131.25 & 94.69 \\
$\mathbf{3}$ & Mixed type & Uncompetitive & 117.20 & 104.20 \\
Quercetin & Mixed type & nt & 27.13 & - \\
Acarbose & nt & Competitive & - & 0.06 \\
\hline
\end{tabular}

nt; not tested 

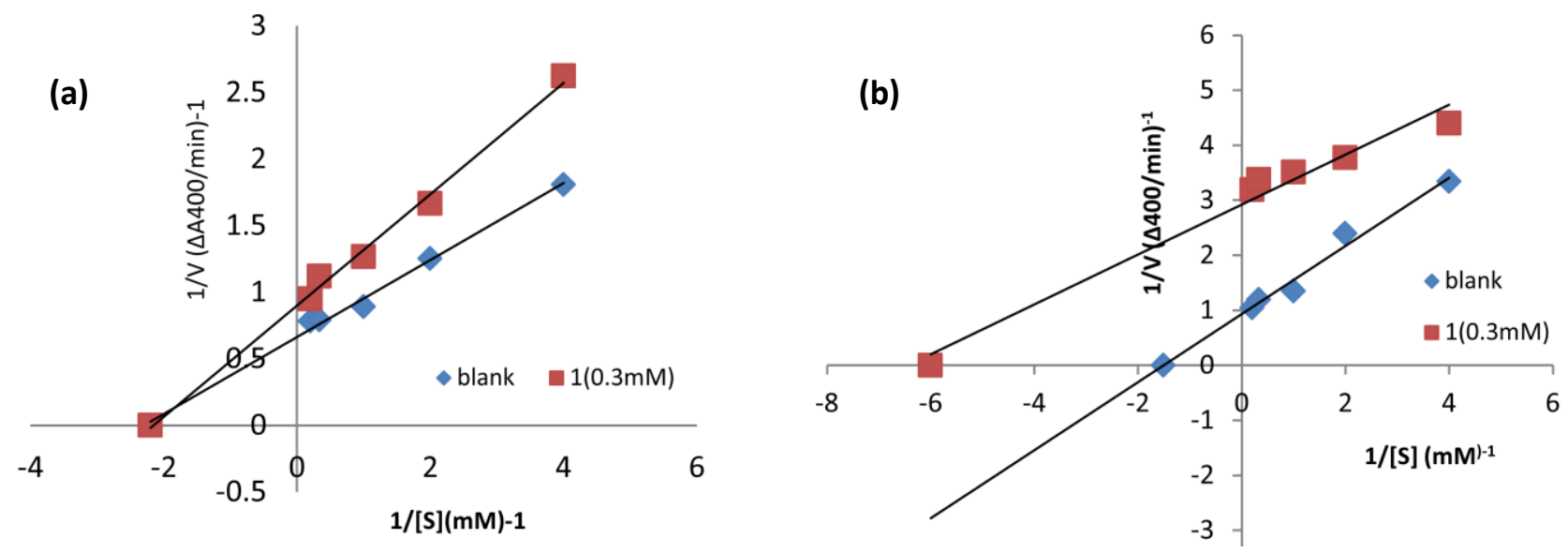

Figure.3 Lineweaver-Burke plots of compound $\mathbf{1}$ against yeast (a) and mammalian $\alpha$-glucosidase (b)
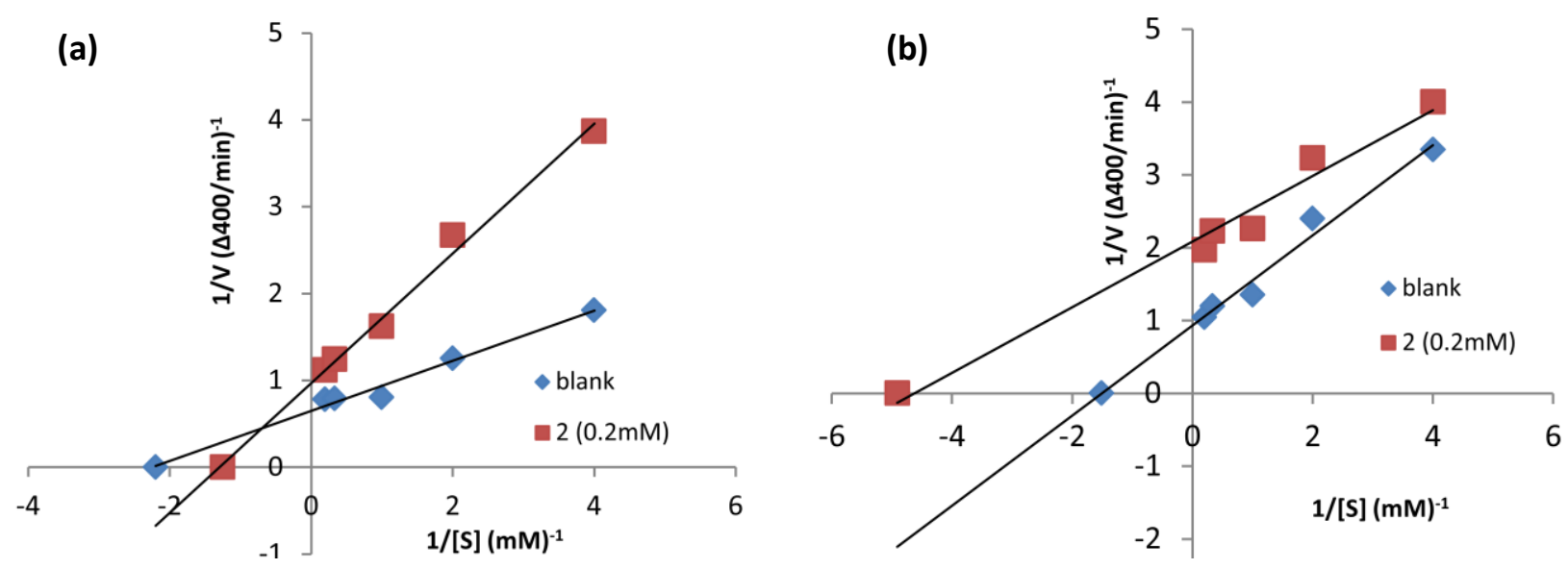

Figure.4 Lineweaver-Burke plots of compound 2 against yeast (a) and mammalian $\alpha$-glucosidase (b)
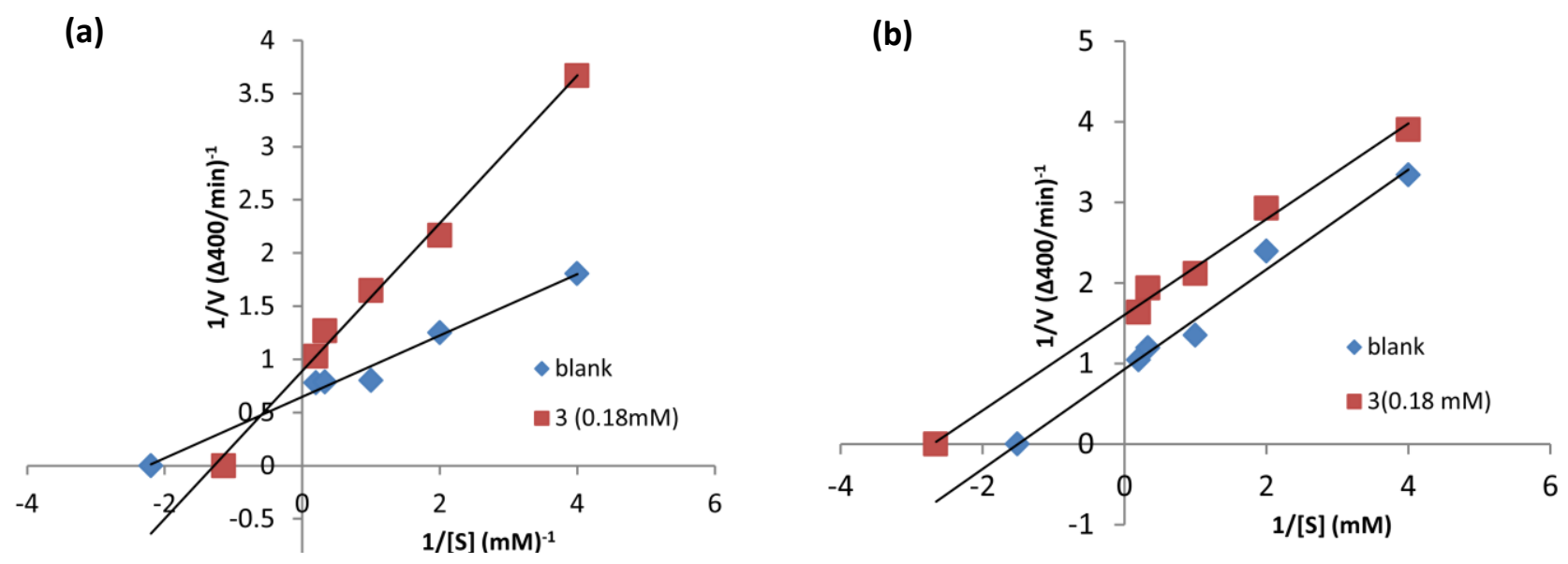

Figure. 5 Lineweaver-Burke plots of compound $\mathbf{3}$ against yeast (a) and mammalian $\alpha$-glucosidase (b) 


\section{CONCLUSION}

Soluchrin (1) a secondary metabolite of terrestrial fungi A. terreus showed potential inhibitory activity against yeast and mammalian $\alpha$ glucosidase. The bromination of sulochrin could increase the inhibitory activity against yeast $\alpha$-glucosidase. These results indicated that sulochrin (1) derived from the A. terreus terrestrial fungi could be employed as a lead compound for the development of new $\alpha$-glucosidase inhibitor.

\section{ACKNOWLEDGMENT}

The authors would likethank Prof. Dr. Muhammad Hanafi and Dr. Nina Artanti for their valuable insights.This research was supported by the program (139/IPT.2/KP/XII/2009) Molecular Farming and Pharmaceutical Material organized by Indonesian Institute of Sciences (LIPI).

\section{REFERENCES}

Dewi RT., Anita Y., Istyastono EP., \&Darmawan A. (2009). The applicability of the crystal structure of Termotoga maritima 4- $\alpha$ glucanotransferase as the template for sulochrin as $\alpha$-glucosidase. Indonesian Journal of Chemistry 9: 487-490.

Dewi RT, Iskandar YM., Hanafi M., Kardono LBS., Angelina M., Dewijanti ID., \&Banjarnahor SDS.
(2007). Inhibitory effect of koji Aspergillus terreus on $\alpha$-glucosidase activity and postprandial hyperglycemia. Pakistan Journal of Biological Science 10: 3131-3135.

Dewi RT., Tachibana S.,\& Darmawan A.(2014). Effect on $\alpha$-glucosidase inhibition and antioxidant activities of butyrolactone derivatives from Aspergillus terreus MC751. Medicinal Chemistry Research 23: 454-460.

Dewi RT., Tachibana S., Fajriah S., \&Hanafi M. (2015). $\alpha$-Glucosidase inhibitor compounds from Aspergillus terreus $\mathrm{RCC} 1$ and their antioxidant activity. Medicinal Chemistry Research 24: 737-743.

Du ZY., Liu RR., Shao WY., Mao XP., Ma L., Gu LQ., Huang ZS., \& Chan ASC. (2006). $\quad \alpha$-Glucosidase inhibitions of natural curcuminoid and curcuminanalogs. European Journal of Medicinal Chemistry41(2): 213-218.

Fujisawa T., Ikegami H., Inoue K., Kawabata Y., \&Ogihara T. (2005). Effect of two $\alpha$-glucosidase inhibitors, voglibose and acarbose, on postprandial hyperglycemia correlates with subjective abdominal symptoms. Metabolism54: 387-390.

Hajjaj H., Peter N., \& Philippe D.(2001) Lovastatin biosynthesis by Aspergillus terreus in a chemically defined medium. Journal Applied and Environment Microbiology 67(6): 2596-2602.

Kimura A., LeeJH., Lee IS., Lee HS., Park KH., Chiba S., \&Kim D.(2004). Two potent competitive inhibitors 
discriminating $\alpha$-glucosidase family I from family II. Carbohydrate Research 339: 1035-1040.

Kim KY., Nguyen TH., Kurihara H., \&Kim SM.(2010). Alphaglucosidase inhibitory activity of bromophenol purified from the red alga Polyopes lancifolia. Journal Food Science 75:145-150.

Kim YM., Jeong YK., Wang MH., Li WY., \&Rhee HI. (2005). Inhibitory effect of pine extract on $\alpha$ glucosidase activity and postprandial hyperglycemia. Nutrition 21:756761.

Kim KY., Nam KA., Kurihara H., \&Kim SM.(2008). Potent $\alpha$-glucosidase inhibitors purified from the red alga Grateloupia elliptica. Phytochemistry 69: 2820-2825.

Li YQ., Zhou FC., Gao F., Bian JS., \&Shan F. (2009). Comparative evaluation of quercetin, isoquercetin and rutin as inhibitors of $\alpha$ glucosidase. Journal Agriculture and Food Chemistry 57: 11463-11468.

Liu M., Hansen PE., \&Lin X. (2011). Bromophenols in marine algae and their bioactivities. Marine Drugs 9: 1273-1292.

Mayur B, Sandesh S., Shruti S., \&Yum S. (2010).Antioxidant and $\alpha$ glucosidase inhibitory properties of Carpesiumabrotanoides L. Journal of Medicinal Plant Research 4(15): 1547-1553.

Mehta A., Zitzmann N., Rudd PM., Block TM, \& Dwek RA. (1998). $\alpha-$ Glucosidase inhibitors as potential broad based anti-viral agents. FEBS Letter 430: 17-22.
Nguyen TH., Um BH.,\&Kim SM.(2011). Two unsaturated fatty acids with potent $\alpha$-glucosidase inhibitory activity purified from the body wall of Sea Cucumber (Stichopus japonicus). Journal of Food Science 76(9): H208-H214.

Ohashi H., Ishikawa M., Ito J., Ueno A, Gleich GJ, Kita H, Kawai H,\&Fukamachi H. (1997). Sulochrin inhibits eosinophil degranulation.The Journal of Antibiotic. 50 (11): 972974.

Sancheti S., Sancheti S., Bafna M., Lee SH., \&Seo SY.(2011). Persimmon leaf (Diospyros kaki), a potent $\alpha$ glucosidase inhibitor and antioxidant: Alleviation of postprandial hyperglycemia in normal and diabetic rats. Journal of Medicinal Plants5: 1652-1658.

Sato S., Okusa N., Ogawa A., Ikenoue T., Seki T., \&Tsuji T. (2005). Identification and preliminary SAR studies of (+)-Geodin as a glucose uptake stimulator for rat adipocytes. Journal of Antibiotic (Tokyo )58: 583-589.

Tadera K., Inami Y., Takamatsu K., \&Matsuoka T. (2006). Inhibition of $\alpha$-glucosidase and $\alpha$-amylase by flavonoids. Journal of Nutrition Science Vitaminol 52: 149-153.

Takahashi T and Miyazawa M.(2012). Potent $\alpha$-glucosidase inhibitors from Safflower (Carthamustinctorius L.) seed. Phytotheraphy Reserach 26: 722-726.

Ueno A., Ohashi H., Nakano T., Kimura K., Shimizu T., Hakojima T., \&Iijima T. (1998). Crystal structure 
of sulochrin derivatives. Chemical and Pharmaceutical Bulletin 46: 1929-1931.

Wang Y., Zheng J., Liu P., Wang W., \&Zhu W.(2011). Three compounds from Aspergillus terreus PT06-2 grown in a high salt medium. Marine
Drugs 9: 1368-1378.

Zhu Y., Yin L., Cheng Y., \&Yamaki K. (2008). Effects of sources of carbon and nitrogen on production of $\alpha$ glucosidase inhibitor by a newly isolated strain of Bacillus subtilis B2. Food Chemistry 109:737-742. 